\title{
АНТИБАКТЕРИАЛЬНЫЕ СВОЙСТВА РАСТИТЕЛЬНЫХ ЭКСТРАКТОВ И ИХ КОМБИНАЦИЙ С АНТИБИОТИКАМИ В ОТНОШЕНИИ ЭКСТРЕМАЛЬНО-АНТИБИОТИКОРЕЗИСТЕНТНЫХ МИКРООРГАНИЗМОВ
}

\author{
() Тапальский Д.В. ${ }^{1}$, Тапальский Ф.Д. ${ }^{2}$ \\ ${ }^{1}$ Гомельский государственный медицинский университет, Гомель, Беларусь \\ ${ }^{2}$ Витебский государственный медицинский университет, Витебск, Беларусь \\ E-mail: tapalskiy@gsmu.by
}

\begin{abstract}
Определены минимальные подавляющие концентрации (МПК) водных настоев 17 официнальных лекарственных растений в отношении антибиотикочувствительных экстремально-антибиотикорезистентных изолятов Pseudomonas aeruginosa и Acinetobacter baumannii. Обнаружена выраженная антибактериальная активность (МПК < 1 мг/мл) водных экстрактов брусники (Vaccinium vitis-idaea), эвкалипта (Eucalyptus viminalis), дуба (Quercus robur), толокнянки (Arctostaphylos uva-ursi). При сочетанном воздействии на микробную клетку водные растительные экстракты не оказывали значимого влияния на антибактериальную активность аминогликозидов, карбапенемов и фторхинолонов. Выявлен универсальный дозозависимый антагонистический эффект растительных экстрактов на микробиологическую эффективность колистина в отношении A. baumannii и P. aeruginosa. Выявлен синергидный антибактериальный эффект $(\Sigma \Phi П К ~ 0,25-0,50)$ комбинации водного экстракта эвкалипта и цефтазидима в отношении 29,2\% экстремальноантибиотикорезистентных штаммов $A$. baumannii, продуцирующих ОХА-карбапенемазы.
\end{abstract}

Ключевые слова: Pseudomonas aeruginosa, Acinetobacter baumannii, лекарственные растения, антибиотики, антибактериальная активность, синергизм.

\section{ANTIBACTERIAL EFFECTS OF HERBAL EXTRACTS AND THEIR COMBINATIONS WITH ANTIBIOTICS IN RELATION TO EXTENSIVELY ANTIBIOTIC-RESISTANT MICROORGANISMS Tapalski D.V. ${ }^{l}$, Tapalski F.D. ${ }^{2}$}

${ }^{1}$ Gomel State Medical University, Gomel, Belarus; ${ }^{2}$ Vitebsk State Medical University, Vitebsk, Belarus

Minimal inhibitory concentrations (MICs) of 17 officinal aqueous medicinal herbal extracts in regard to antibioticsensitive and extensively antibiotic-resistant $P$. aeruginosa and $A$. baumannii isolates were determined. The expressed antibacterial activity (MIC $<1 \mathrm{mg} / \mathrm{mL}$ ) was found for aqueous cowberry (Vaccinium vitis-idaea), eucalyptus (Eucalyptus viminalis), oak (Quercus robur), and bearberry (Arctostaphylos uva-ursi) extracts. Aqueous herbal extracts did not influence significantly the antibacterial activity of aminoglycosides, carbapenems and fluoroquinolones during their combined action on a microbial cell. A universal dose-dependent antagonistic effect of herbal extracts on the colistin microbiological efficacy in relation to A. baumannii and $P$. aeruginosa was revealed. A synergistic antibacterial effect ( $\Sigma$ FIC 0.25-0.50) of the combination of aqueous eucalyptus extract with the ceftazidime against $29.2 \%$ of OXA-carbapenemase producing A. baumannii strains was detected. ergism.

Keywords: Pseudomonas aeruginosa, Acinetobacter baumannii, medicinal herbs, antibiotics, antibacterial activity, syn-

P. aeruginosa и A. baumannii относятся к наиболее частым возбудителям инфекций, связанных с оказанием медицинской помощи. Важной особенностью этих микроорганизмов является способность к быстрому формированию устойчивости к большинству антимикробных препаратов (АМП) $[1,3]$ с формированием состояния экстремальной антибиотикорезистентности (XDR extensively drug resistance, нечувствительность по крайне мере к одному АМП во всех категориях AMП, за исключением 1-2 категорий) и панрезистентности (PDR - pandrug resistance, нечувствительность ко всем АМП во всех категориях) [11]. Важной причиной развития XDR является продукция карбапенемаз (карбапенемазы ОХА-23, OXA-40, OXA-56 у A. baumannii, металло- $\beta$ лактамазы VIM и IMP у P. aeruginosa). Продукция карбапенемаз как правило, ассоциирована с устойчивостью к большинству не $\beta$-лактамных АМП, за исключением полимиксинов [2].

Ведется поиск и изучение свойств антибактериальных веществ растительного происхождения, активных в отношении антибиотикорезистентных бактерий, особенно в странах с развитой традиционной медициной [4]. Разработана методология скрининга растительного лекарственного сырья на присутствие микробиологически активных соединений [6]. Изучается возможность использования фитотерапии для лечения инфекций, вызванных XDR-патогенами $[7,16]$. Показана бактерицидная активность ряда растительных экстрактов в отношении штаммов $P$. aeruginosa и A. baumannii с множественной устойчивостью к АМП $[5,9,12]$. Одним из перспективных направлений является изучение фармакодинамических взаимодействий вторичных метаболитов расте- 
ний с антибактериальной активностью и АМП. Описан ряд сочетаний растительных экстрактов и АМП, оказывающих синергидный (взаимно усиливающий) эффект при совместном воздействии на бактериальную клетку $[5,14]$.

Цель работы - оценить антибактериальную активность официнальных лекарственных растений в отношении XDR грамотрицательных бактерий и выявить комбинации АМП и растительных экстрактов, обладающих синергидной активностью.

\section{МАТЕРИАЛЫ И МЕТОДЫ ИССЛЕДОВАНИЯ}

В исследование включено 17 наименований официнальных лекарственных растений в виде сухого измельченного растительного сырья, приобретенных в аптечной сети (таблица 1).

Для приготовления настоев к 10 г растительного сырья добавляли 100 мл дистиллированной воды, флаконы кипятили на водяной бане в течение 10 мин и охлаждали 45 мин при комнатной температуре. Настои фильтровали через марлевый и бумажный фильтры, затем проводили стерилизующую фильтрацию с помощью фильтров Filtropur S 0,45 (Sarstedt, Германия). До выполнения микробиологических исследований настои хранили при $6^{\circ} \mathrm{C}$ не более 24 ч. Для определения суммарной концентрации растворенных веществ в полученных настоях проводили выпаривание 10 мл настоя в течение 12 ч при $44^{\circ} \mathrm{C}$ с последующим взвешиванием полученного сухого водного экстракта на аналитических весах.

В исследование включены контрольные штаммы микроорганизмов Escherichia coli ATCC 25922 и P. aeruginosa ATCC 27853, а также 2 антибиотикочувствительных и $32 \mathrm{XDR}$ изолята $P$. aeruginosa и A. baumannii.

Определение минимальных подавляющих концентраций (МПК) и минимальных бактерицидных концентраций (МБК) водных растительных экстрактов проводили методом последовательных микроразведений в бульоне МюллераХинтона. Готовили 11-серийных двукратные разведения в лунках 96-луночных планшетов и вносили стандартизованные по оптической плотности суспензии тестируемых бактериальных культур (конечная концентрация $10^{6}$ клеток/мл). Планшеты закрывали крышками, помещали в герметичные полиэтиленовые пакеты и инкубировали 18 ч $-35^{\circ} \mathrm{C}$ с постоянным орбитальным встряхиванием 90 об/мин (шейкер-инкубатор ES-20, Biosan, Латвия).

Учет МПК выполняли визуально по отсутствию видимого роста микроорганизмов. Для определения МБК делали высев 10 мкл из каждой лунки на сектор плотной питательной среды (ГРМ-агар), чашки инкубировали в течение $16-18$ ч при $35^{\circ} \mathrm{C}$ и оценивали рост на плотной среде. Минимальную концентрацию водного экстракта, подавляющую бактериальный рост на $99,9 \%$ (отсутствие роста или рост не более 1 колонии микроорганизмов в секторе), указывали как МБК.

Для растительных экстрактов с выраженной антибактериальной активностью (МПК $\leq 1$ мг/мл [17]) оценивали эффективность сочетанного воздействия в комбинациях с AMП на XDR штаммы

Таблица 1

Образцы растительного сырья, включенные в исследование

\begin{tabular}{|c|l|c|c|}
\hline $\begin{array}{c}\text { № } \\
\text { п/п }\end{array}$ & \multicolumn{1}{|c|}{ Видовое название } & $\begin{array}{c}\text { Часть } \\
\text { растения }\end{array}$ & Производитель \\
\hline 1 & Багульник болотный (Ledum palustre) & побеги & ООО «Падис'с», Беларусь \\
\hline 2 & Береза белая (Betula alba) & почки & ООО «НПК Биотест», Беларусь \\
\hline 3 & Брусника обыкновенная (Vaccinium vitis-idaea) & листья & 3АО «БелАсептика», Беларусь \\
\hline 4 & Дуб обыкновенный (Quercus robur) & кора & ООО «НПК Биотест», Беларусь \\
\hline 5 & Душица обыкновенная (Origanum vulgare) & трава & ООО «Калина», Беларусь \\
\hline 6 & Зверобой продырявленный (Hypericum perforatum) & трава & ООО «НПК Биотест», Беларусь \\
\hline 7 & Календула лекарственная (Calendula officinalis) & цветки & ООО «Калина», Беларусь \\
\hline 8 & Можжевельник обыкновенный (Juniperus communis) & плоды & ООО «НПК Биотест», Беларусь \\
\hline 9 & Мята перечная (Mentha piperita) & листья & ООО «НПК Биотест», Беларусь \\
\hline 10 & Подорожник большой (Plantago major) & листья & ООО «НПК Биотест», Беларусь \\
\hline 11 & Ромашка аптечная (Chamomilla recutita) & цветки & ООО «НПК Биотест», Беларусь \\
\hline 12 & Толокнянка обыкновенная (Arctostaphylos uva-ursi) & листья & ООО «НПК Биотест», Беларусь \\
\hline 13 & Тысячелистник обыкновенный (Achillea millefolium) & трава & ООО «Падис'с», Беларусь \\
\hline 14 & Хвощ полевой (Equisetum arvense) & трава & ООО «НПК Биотест», Беларусь \\
\hline 15 & Чабрец (тимьян ползучий) (Thymus serpyllum) & трава & ООО «НПК Биотест», Беларусь \\
\hline 16 & Шалфей лекарственный (Salvia officinalis) & листья & ООО «НПК Биотест», Беларусь \\
\hline 17 & Эвкалипт прутовидный (Eucalyptus viminalis) & листья & ООО «Алтайфарм», Россия \\
\hline
\end{tabular}


A. baumannii и $P$. aeruginosa. В расплавленный и остуженный до $45^{\circ} \mathrm{C}$ агар Мюллера-Хинтона вносили растительные экстракты для обеспечения концентрации 1/4 от МПК и 1/8 от МПК. Полученные среды разливали в полистироловые чашки Петри. В качестве контроля использовали чашки с МХА без добавления растительных экстрактов. Опытные и контрольные чашки инокулировали бактериальными суспензиями (0,5 МакФарланд) и автоматическим диспенсером наносили по 8 дисков с АМП (BD Sensi-Disc Susceptibility Test Discs, Becton Dickinson, США): амикацин 30 мкг, тобрамицин 30 мкг, имипенем 10 мкг, меропенем 10 мкг, цефтазидим 30 мкг, ципрофлоксацин 5 мкг, тигециклин 15 мкг, колистин 10 мкг.

После инкубации 18 ч при $35^{\circ} \mathrm{C}$ измеряли диаметры зон подавления роста вокруг дисков, сравнивали диаметры на опытных и контрольных чашках. При уменьшении диаметра зоны подавления роста вокруг диска с АМП в присутствии растительного экстракта на 3 мм и более по сравнению с контролем эффект взаимодействия считали антагонистическим, при увеличении на 3 мм и более - синергидным.

Для более точной количественной оценки выявленной синергидной активности проведено определение фракционных подавляющих концентраций (ФПК) АМП в присутствии растительного экстракта методом «шахматной доски» [18] в диапазоне концентраций от $1 / 16^{*}$ МПК до 4*МПК. Заданные концентрации АМП и растительного экстракта готовились в бульоне Мюллера-Хинтона и в объеме 100 мкл вносились в 64 ячейки $(8 \times 8)$ стерильного полистиролового 96-луночного планшета (общий объем среды в каждой ячейке - 200 мкл), после чего планшет инокулировали суспензией исследуемой культуры (конечная концентрация микробных клеток $\approx$ $5 * 10^{5}$ клеток/мл) и инкубировали в течение 18 часов при $35^{\circ} \mathrm{C}$ в шейкере-инкубаторе с непрерывным низкоамплитудным встряхиванием. Учет результатов проводили по сравнению с контролем (рост в ячейке со средой, не содержащей АМП). Рассчитывали ФПК для АМП и растительного экстракта в комбинации:

$$
\begin{aligned}
& \Phi \Pi K_{\mathrm{A}}=\mathrm{M \Pi K}_{\mathrm{AЭ}} / \mathrm{M \Pi K}_{\mathrm{A}} \\
& \Phi \Pi \kappa_{\ni}=\mathrm{M \Pi K}_{Э \mathrm{~A}} / \mathrm{M \Pi K}_{\ni},
\end{aligned}
$$

где МПК тельного экстракта, МПК бавления растительного экстракта, МПК ЭА МПК растительного экстракта в присутствии АМП, МПК - МПК растительного экстракта без добавления АМП.

Индекс ФПК рассчитывался как сумму ФПК:

$$
\Sigma \Phi П К=Ф П К_{\mathrm{A}}+\Phi П К_{\mathrm{B}}
$$

При $\Sigma Ф П К ~ \leq 0,5$ эффект комбинации оценивался как синергидный, при $0,5<\Sigma Ф П К ~ \leq 1-$ как аддитивный, при $1<\Sigma Ф П К \leq 4-$ как нейтральный.

\section{РЕЗУЛЬТАТЫ ИССЛЕДОВАНИЯ И ИХ ОБСУЖДЕНИЕ}

Выраженная антибактериальная активность (MПК $\leq 1$ мг/мл) в отношении как XDR, так и антибиотикочувствительных изолятов $P$. aeruginosa и A. baumannii выявлена для водного экстракта брусники обыкновенной (МПК 0,35-0,78 мг/мл). Экстракты эвкалипта прутовидного и дуба обыкновенного проявляли выраженную антибактериальную активность в отношении клинических $\mathrm{XDR}$ изолятов P. aeruginosa (МПК 0,630,75 мг/мл). Водный экстракт толокнянки обыкновенной подавлял рост всех включенных в исследование изолятов A. baumannii (МПК 0,380,78 мг/мл). Экстракты брусники обыкновенной, эвкалипта прутовидного, дуба обыкновенного, толокнянки обыкновенной также оказывали выраженное антибактериальное действие на контрольную культуру E. coli ATCC 25922 (МПК 0,38-0,75 мг/мл). Для остальных экстрактов отмечена меньшая выраженность антибактериальных свойств (МПК $>1$ мг/мл). Минимальные бактерицидные концентрации для большинства растительных экстрактов были равны МПК или отличались от нее не более чем на одно разведение.

Исследование сочетанного воздействия в комбинациях с АМП выполнено для 4 растительных экстрактов с выявленной высокой антибактериальной активностью (экстракты брусники обыкновенной, эвкалипта прутовидного, дуба обыкновенного, толокнянки обыкновенной). Данные экстракты в концентрациях 1/4 и 1/8 от МПК не оказывали значимого влияния на активность аминогликозидов (амикацин, тобрамицин), карбапенемов (имипенем, меропенем) и фторхинолонов (ципрофлоксацин). Все водные экстракты оказывали универсальный антагонистический эффект на антибактериальную активность колистина в отношении всех штаммов $P$. aeruginosa и A. baumannii, что может объясняться ограничениями диско-диффузионного метода. Большая молекулярная масса полимиксинов (969 для колистина) затрудняет диффузию АМП в питательной среде. Компоненты растительных экстрактов могут оказывать модифицирующее воздействие на структуру входящего в состав среды агар-агара и замедлять диффузию колистина.

B отношении XDR штаммов A. baumannii БА026 и A. baumannii БА-032 выявлен синергидный эффект комбинации цефтазидима и водных растительных экстрактов, наиболее выраженный для водного экстракта эвкалипта прутовидного (таблица 2). 
Таблица 2

Эффекты сочетанного воздействия экстракта эвкалипта прутовидного и цефтазидима на микроорганизмы

\begin{tabular}{|l|c|c|c|c|}
\hline \multirow{2}{*}{} & \multicolumn{2}{|c|}{ Диаметр зоны подавления роста, мм } & \multirow{2}{*}{ Эффект } \\
\cline { 2 - 4 } взаимодействия & $1 / 4$ МПК & $1 / 8$ МПК & контроль & С \\
\hline A. baumannii БА-026 & 16 & 13 & 9 & С \\
\hline A. baumannii БА-032 & 17 & 15 & 10 & $\mathrm{H}$ \\
\hline P. aeruginosa БП-056 & 23 & 25 & 25 & $\mathrm{H}$ \\
\hline P. aeruginosa БП-074 & 25 & 30 & 27 & $\mathrm{H}$ \\
\hline P. aeruginosa АТСС 27853 & 30 & 30 & 30 & \\
\hline
\end{tabular}

Примечание: Н - нейтральный эффект, С - синергидный эффект.

Таблица 3

Эффекты сочетанного воздействия экстракта эвкалипта прутовидного и цефтазидима на XDR клинические изоляты $A$. baumannii

\begin{tabular}{|c|c|c|c|c|c|c|c|}
\hline \multirow[t]{2}{*}{$\begin{array}{l}\text { № } \\
\Pi / \Pi\end{array}$} & \multirow{2}{*}{$\begin{array}{l}\text { Микро- } \\
\text { организм }\end{array}$} & \multirow[t]{2}{*}{ Лаб. № } & \multirow{2}{*}{$\begin{array}{c}\text { Карба- } \\
\text { пенемаза }\end{array}$} & \multicolumn{2}{|c|}{$\begin{array}{c}\text { Цефтазидим, } \\
\text { диаметр зон подавления } \\
\text { роста (мм) }\end{array}$} & \multirow{2}{*}{$\begin{array}{c}\text { Характер } \\
\text { взаимодействия }\end{array}$} & \multirow[t]{2}{*}{$\Sigma Ф П К$} \\
\hline & & & & $\begin{array}{l}\text { эвкалипт, } \\
\text { 1/8 МПК }\end{array}$ & контроль & & \\
\hline 1 & A. baumannii & БА-005 & OXA-40 & 8 & 6 & $\mathrm{H}$ & \\
\hline 2 & A. baumannii & БА-006 & OXA-40 & 26 & 22 & $\mathrm{H}$ & \\
\hline 3 & A. baumannii & БА-007 & OXA-40 & 14 & 11 & C & 0,50 \\
\hline 4 & A. baumannii & БА-011 & OXA-40 & 6 & 6 & $\mathrm{H}$ & \\
\hline 5 & A. baumannii & БА-012 & OXA-40 & 6 & 6 & $\mathrm{H}$ & \\
\hline 6 & A. baumannii & БА-026 & OXA-40 & 12 & 6 & $\mathrm{C}$ & 0,25 \\
\hline 7 & A. baumannii & БА-029 & OXA-40 & 6 & 6 & $\mathrm{H}$ & \\
\hline 8 & A. baumannii & БА-032 & OXA-40 & 14 & 7 & $\mathrm{C}$ & 0,38 \\
\hline 9 & A. baumannii & $\mathrm{A}-010$ & OXA-40 & 14 & 10 & $\mathrm{C}$ & 0,5 \\
\hline 10 & A. baumannii & A-019 & OXA-40 & 6 & 6 & $\mathrm{H}$ & \\
\hline 11 & A. baumannii & A-034 & $\begin{array}{c}\text { OXA-23+ } \\
\text { OXA-40 } \\
\end{array}$ & 10 & 9 & $\mathrm{H}$ & \\
\hline 12 & A. baumannii & A-036 & $\begin{array}{c}\text { OXA-23+ } \\
\text { OXA-40 }\end{array}$ & 12 & 8 & $\mathrm{C}$ & 0,5 \\
\hline 13 & A. baumannii & A-041 & OXA-23 & 15 & 12 & $\mathrm{C}$ & 0,75 \\
\hline 14 & A. baumannii & A-042 & OXA-40 & 6 & 6 & $\mathrm{H}$ & \\
\hline 15 & A. baumannii & A-047 & OXA-23 & 6 & 6 & $\mathrm{H}$ & \\
\hline 16 & A. baumannii & A-049 & OXA-40 & 6 & 6 & $\mathrm{H}$ & \\
\hline 17 & A. baumannii & $\mathrm{A}-050$ & OXA-40 & 6 & 6 & $\mathrm{H}$ & \\
\hline 18 & A. baumannii & A-053 & OXA-40 & 6 & 6 & $\mathrm{H}$ & \\
\hline 19 & A. baumannii & A-054 & OXA-40 & 12 & 9 & $\mathrm{C}$ & 0,75 \\
\hline 20 & A. baumannii & A-057 & OXA-40 & 6 & 6 & $\mathrm{H}$ & \\
\hline 21 & A. baumannii & A-059 & OXA-40 & 13 & 8 & $\mathrm{C}$ & 0,50 \\
\hline 22 & A. baumannii & A-065 & OXA-40 & 14 & 7 & $\mathrm{C}$ & 0,38 \\
\hline 23 & A. baumannii & A-075 & OXA-40 & 6 & 6 & $\mathrm{H}$ & \\
\hline 24 & A. baumannii & A-076 & OXA-40 & 6 & 6 & $\mathrm{H}$ & \\
\hline
\end{tabular}

Примечание: $\mathrm{H}$ - нейтральный эффект, С - синергидный эффект.

Для более детальной оценки эффективности синергидного взаимодействия водного настоя эвкалипта и цефтазидима из рабочей коллекции отобрано 24 штамма A. baumannii, устойчивых к большинству $\beta$-лактамных АПМ, включая карбапенемы. Все отобранные штаммы являлись продуцентами ОХА-карбапенемаз (таблица 3). Синергидный эффект был выявлен для 9 из 24 штаммов $(37,5 \%)$, при этом для 7 из них $(29,2 \%)$ он подтвержден методом «шахматной доски» ( $Ф$ ФК 0,25-0,50). 
Выявлен синергидный антибактериальный эффект ( $\Sigma$ ФПК 0,25-0,50) комбинации водного экстракта из эвкалипта прутовидного и цефтазидима в отношении $29,2 \%$ XDR штаммов A. baumannii, продуцирующих ОХА-карбапенемазы. Отсутствие аналогичного влияния на активность карбапенемов позволяет предположить, что механизм обнаруженного эффекта не связан с блокированием ферментативной активности карбапенемаз, а вызван, скорее, восстановлением проницаемости клеточной стенки для АМП или блокированием эффлюксных систем в результате воздействия отдельных компонентов растительного экстракта.

В доступной литературе имеются многочисленные указания на выраженную антибактериальную активность экстрактов и эфирных масел, получаемых из листьев эвкалиптов различных видов [15]. В работе F.M. Reda выявлен синергидный антибактериальный эффект метанолового экстракта из листьев E. camaldulensis в сочетании с гентамицином или цефтриаксоном в отношении штаммов $S$. aureus и $P$. aeruginosa, антибактериальная активность в отношении $A$. baumannii авторами не исследовалась [14]. Заслуживает внимания выраженная бактерицидная активность дербенника иволистного (Lythrum salicaria) в отношении A. baumannii и P. aeruginosa, выявленная в работе E. Guclu [8]. Предложено использование экстрактов из L. salicaria для местной антисептической терапии при инфекциях кожи и мягких тканей, инфекций ожоговых ран, диабетической стопы, вызванных MDR и XDR грамотрицательными возбудителями. Известно, что L. salicaria широко используется в традиционной медицине еще с античных времен, в том числе перорально в виде настоев и отваров, например для лечения диареи, а также местно для лечения трофических язв и инфекционных поражений кожи [10].

В работе Y. Miyasaki скрининг антибактериальной активности 60 различных растений, выполненный методом микроразведений в бульоне, позволил выявить несколько экстрактов, высокоактивных в отношении MDR штаммов A. baumannii, в том числе экстракты харитаки (Terminalia chebula), шиповника морщинистого (Rosa rugosa) и шлемника байкальского (Scutellaria baicalensis) [12]. В дальнейшем при хроматографическом разделении веществ, входящих в состав растительных экстрактов, и определении антибактериальной активности каждой из фракций был выделен и идентифицирован норвогонин, МПК и МБК которого для клинически значимых XDR штаммов A. baumannii составили соответственно 0,128 мг/мл и 0,256 мг/мл. Норвогонин выделен из экстракта шлемника бай- кальского - растения, используемого в традиционной медицине, в том числе в качестве местного антисептика [13]. Однако при изучении сочетанного воздействия норвогонина совместно с синтетическими АМП различных классов не обнаружено ни одной комбинации с синергидной антибактериальной активностью на антибиотикорезистентные штаммы $A$. baumannii.

Определенные в настоящем исследовании МПК водных экстрактов из нескольких растений Беларуси сопоставимы с МПК норвоганина для A. baumannii $(0,128$ мг/мл) [13], хотя и превышают ее в 3-6 раз. Так, МПК экстракта брусники обыкновенной и толокнянки обыкновенной составили для карбапенемаза-продуцирующих штаммов $A$. baumannii 0,35-0,78 мг/мл. Поскольку полученные экстракты представляют собой совокупность различных веществ, выделение из их состава вторичных метаболитов, обусловливающих антибактериальную активность, позволит получить антисептические препараты с более низкими значениями МПК для A. baumannii и других XDR грамотрицательных микроорганизмов.

Таким образом, МПК водных растительных экстрактов значительно (в десятки и сотни раз) превышают МПК АМП для антибиотикочувствительных штаммов. Однако в случае инфекций, вызванных XDR микроорганизмами с высокими значениями МПК АМП, можно рассматривать возможность проведения фитотерапии в качестве дополнения к проводимой системной антибиотикотерапии. При сочетанном воздействии на микробную клетку водные растительные экстракты не оказывают значимого влияния на антибактериальную активность аминогликозидов, карбапенемов и фторхинолонов. Только для комбинации водного экстракта эвкалипта прутовидного и цефтазидима выявлен синергидный антибактериальный эффект в отношении некоторых XDR штаммов A. baumannii, продуцирующих OXА-карбапенемазы.

\section{ЛИТЕРАТУРА / REFERENCES}

1. Сухорукова М.В., Эйдельштейн М.В., Склеенова Е.Ю., Иванчик Н.В., Шек Е.А., Дехнич А.В., Козлов Р.С., исследовательская группа «МАРАФОН». Антибиотикорезистентность нозокомиальных штаммов Acinetobacter spp. в стационарах России: результаты многоцентрового эпидемиологического исследования «МАРАФОН» 2013-2014 // Клиническая микробиология и антимикробная химиотерапия. - 2017. - Т. 19, № 1. - C. 42-48. [Sukhorukova M.V., Edelstein M.V., Skleenova E.Yu., Ivanchik N.V., Shek E.A., Dekhnich A.V., Kozlov R.S., «MARATHON» study group. Antimicrobial resistance of nosocomial Acinetobacter spp. isolates in Russia: results of multicenter epidemiological study «MAR- 
ATHON» 2013-2014. Klinicheskaya mikrobiologiya i antimikrobnaya khimioterapiya. 2017; 19 (1): 42-48. (in Russ.)].

2. Тапальский Д.В., Осипов В.А., Жаворонок С.В. Карбапенемазы грамотрицательных бактерий: распространение и методы детекции // Медицинский журнал. - 2012. - № 2. - С. 10-15. [Tapalski D.V., Osipov V.A., Zhavoronok S.V. Carbapenemases of gram-negative pathogens: spread and methods of detection. Meditsinskiy zhurnal. 2012; (2): 10-15. (in Russ.)].

3. Эйдельштейн М.В., Сухорукова М.В., Склеенова Е.Ю., Иванчик Н.В., Микотина А.В., Шек Е.А. Дехнич А.В., Азизов И.С., Козлов Р.С. Антибиотикорезистентность нозокомиальных штаммов Pseudomonas aeruginosa в стационарах России: результаты многоцентрового эпидемиологического исследования «МАРАФОН» 2013-2014 // Клиническая микробиология и антимикробная химиотерапия. - 2017. - Т. 19, № 1. - С. 37-41. [Edelstein M.V., Sukhorukova M.V., Skleenova E.Yu., Ivanchik N.V., Mikotina A.V., Sheck E.A., Dekhnich A.V., Azizov I.S., Kozlov R.S. «MARATHON» study group. Antimicrobial resistance of nosocomial Pseudomonas aeruginosa isolates in Russia: results of multicenter epidemiological study «MARATHON» 2013-2014. Klinicheskaya mikrobiologiya i antimikrobnaya khimioterapiya. 2017; 19 (1): 37-41 (in Russ.)].

4. Abdallah E.M. Plants: an alternative source for antimicrobials // Journal of Applied Pharmaceutical Science. - 2011. - Vol. 1, N 6. - P. 16-20.

5. Adwan G., Abu-Shanab B., Adwan K. Antibacterial activities of some plant extracts alone and in combination with different antimicrobials against multidrugresistant Pseudomonas aeruginosa strains // Asian Pacific Journal of Tropical Medicine. - 2010. - Vol. 3, N 4. - P. 266-269. - DOI: 10.1016/S19957645(10)60064-8.

6. Das K., Tiwari R.K.S., Shrivastava D.K. Techniques for evaluation of medicinal plant products as antimicrobial agent: current methods and future trends // Journal of Medicinal Plants Research. - 2010. Vol. 4, N 2 - P. 104-111. - DOI: 10.5897/JMPR09.03.

7. Djeussi D.E., Noumedem J.A., Seukep J.A., Fankam A.G., Voukeng I.K., Tankeo S.B., Nkuete A.H., Kuete $V$. Antibacterial activities of selected edible plants extracts against multidrug-resistant Gramnegative bacteria // BMC Complementary and Alternative Medicine. - 2013. - Vol. 13. - P. 164. - DOI: 10.1186/1472-6882-13-164.

8. Guclu E., Genc H., Zengin M., Karabay O. Antibacterial activity of Lythrum salicaria against multidrugresistant Acinetobacter baumannii and Pseudomonas aeruginosa // Annual Research and Review in Biology - 2014. - Vol. 4, N 7. - P. 1099-1105. - DOI: 10.9734/ARRB/2014/7357.

9. Heidary M., Hashemi A., Goudarzi H., Khoshnood S., Roshani M., Azimi H., Goudarzi M. The antibacterial activity of Iranian plants extracts against metallo betalactamase producing Pseudomonas aeruginosa strains // Journal of Paramedical Sciences. - 2016. Vol 7, N 1. - $\quad$ P. 13-19. - DOI: 10.22037/jps.v7i1.11203.

10. Humadi S.S., Istudor V. Lythrum salicaria (purple loosestrife). Medicinal use, extraction and identification of its total phenolic compounds // FARMACIA. 2009. - Vol. 57, N 2. - P. 192-200.

11. Magiorakos A.P., Srinivasan A., Carey R.B., Carmeli Y., Falagas M.E., Giske C.G., Harbarth S., Hindler J.F., Kahlmeter G., Olsson-Liljequist B., Paterson D.L., Rice L.B., Stelling J., Struelens M.J., Vatopoulos A., Weber J.T., Monnet D.L. Multidrugresistant, extensively drug-resistant and pandrugresistant bacteria: an international expert proposal for interim standard definitions for acquired resistance // Clinical Microbiology and Infection. - 2012. Vol. 18, N 3. - P. 268-281. - DOI: 10.1111/j.14690691.2011.03570.x.

12. Miyasaki Y., Nichols W.S., Morgan M.A., Kwan J.A., Van Benschoten M.M., Kittell P.E., Hardy W.D. Screening of herbal extracts against multi-drug resistant Acinetobacter baumannii // Phytotherapy Research. - 2010. - Vol. 24, N 8. - P. 1202-1206. DOI: $10.1002 /$ ptr.3113.

13. Miyasaki Y., Rabenstein J.D., Rhea J., Crouch M.-L., Mocek U.M., Kittell P.E., Morgan M.A., Nichols W.S., Van Benschoten M. M., Hardy W.D., Liu G.Y. Isolation and characterization of antimicrobial compounds in plant extracts against multidrug-resistant Acinetobacter baumannii // PLoS One. - 2013. - Vol. 8, N 4. - Art. e61594. - $\quad$ DOI: 10.1371/journal.pone.0061594.

14. Reda F.M., El-Zawahry Y.A., Omar A.R. Synergistic effect of combined antibiotic and methanol extract of Eucalyptus camaldulensis leaf against Staphylococcus aureus and Pseudomonas aeruginosa // International Journal of Applied Sciences and Biotechnology. 2017. - Vol 5, N 4. - P. 486-497. - DOI: 10.3126/ijasbt.v5i4.18620.

15. Sebei K., Sakouhi F., Herchi W., Khouja M.L., Boukhchina $S$. Chemical composition and antibacterial activities of seven Eucalyptus species essential oils leaves // Biological Research. - 2015. - Vol. 48, N 1. - P. 7. - DOI: 10.1186/0717-6287-48-7.

16. Srivastava J., Chandra H., Nautiya A.R., Kalra S.J.S. Antimicrobial resistance and plant-derived antimicrobials as an alternative drug line to control infections // 3 Biotech. - 2014. - Vol. 4, N 5 - P. 451-460. - DOI: 10.1007/s13205-013-0180-y.

17. Tegos G., Stermitz F.R., Lomovskaya O., Lewis K. Multidrug pump inhibitors uncover remarkable activity of plant antimicrobials // Antimicrobial Agents and Chemotherapy. - 2002. - Vol. 46, N 10. P. 3133-3141. - DOI: 10.1128/AAC.46.10.31333141.2002.

18. White R.L., Burgess D.S., Manduru M., Bosso J.A. Comparison of three different in vitro methods of detecting synergy: time-kill, checkerboard, and E test // Antimicrobial Agents and Chemotherapy. - 1996. Vol. 40, N 8. - P. 1914-1918. 